\title{
CAPÍTULO 10 \\ CADEIA CINZA DA RECICLAGEM: MAPEAMENTO DA ROTA DE MATERIAIS RECICLÁVEIS PÓS-CONSUMO EM CRICIÚMA E REGIÃO
}

DOI: http://dx.doi.org/10.18616/pgt10

Mário Ricardo Guadagnin Sabrina Baesso Cadorin Leandro Nunes Danrlei de Conto

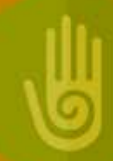

SUMÁRIO 


\section{INTRODUÇÃO}

A compreensão da cadeia de reciclagem em suas relações e operações que ocorrem desde a catação, separação e triagem com identificação dos diferentes atores, elos e enlaces que são estabelecidas nas etapas: consumo, geração, destinação e descarte para coleta seletiva ou apenas disposição e deposição em contentores e lixeiras é necessária para implementar o gerenciamento integrado de resíduos sólidos urbanos.

Nas idas e vindas, nas buscas pela rota dos resíduos recicláveis, quem percorrer o caminho reverso de uma latinha ou de um saco plástico nesta indigesta cidade visível para poucos irá perceber que as ruas, avenidas, vielas, estruturas de separação e triagem em galpões e empresas escondem no percurso os grilhões e grilhetas que prendem pés e mãos de catadores e catadoras que fazem da triagem de materiais o exercício de profissão para alimentar o mercado e a cadeia cinza da reciclagem.

$\mathrm{Na}$ paisagem da urbe, a identificação e reconhecimento da atuação de mãos de atores visíveis e invisíveis de catadores autônomos independentes ou organizados em associações e cooperativas e os diferentes níveis de canais de comercialização com a estrutura hierárquica de intermediários recicladores-distribuidores que catam, separam, segregam, classificam, enfardam e comercializam materiais recicláveis (recicladores-beneficiadores) para empresas de transformação e reciclagem (recicladores-transformadores), terminologia de atores proposta por Conceição et al. (2016), são etapas fundamentais na análise dos processos de gestão e gerenciamento integrado de resíduos sólidos com a inclusão social e efetivação da reciclagem definida conforme a Lei 12.305/2010 como o "processo de transformação dos resíduos sólidos que envolve a alteração de suas propriedades físicas, físico-químicas ou biológicas, com vistas à transformação em insumos ou novos produtos" (BRASIL, 2010, Capítulo II, Artigo 3ำ, Inciso XIV).

A Coleta Seletiva está imbricada com diversos fatores, desde a saúde do trabalhador que irá coletar os materiais, os aspectos econômicos 
de geração de renda até as metas e diretrizes de gestão dos resíduos sólidos urbanos, conforme preconiza a Política Nacional de Resíduos Sólidos. Para que ocorra a coleta seletiva de maneira efetiva, os setores sociais (catadores autônomos, catadores organizados e sociedade civil) precisam estar articulados e pautarem reivindicações junto à gestão pública politicamente no exercício do controle social.

Conhecer a cadeia de reciclagem, desde a coleta dos resíduos sólidos urbanos até o processamento final das diferentes subclasses de resíduos recicláveis (papel e papelão, plástico, metal, vidro), é essencial para a compreensão da realidade enfrentada por catadores e catadoras diariamente e o entendimento da forma com que os pequenos intermediários (distribuidor - reciclador-distribuidor), médios intermediários (reciclador-distribuidor / reciclador-beneficiador) e grandes sucateiros e empresas transformadoras (reciclador-transformador) atuam e trabalham criando elos e enlaces, bem como trazer à tona para a sociedade a ingerência pública frente à questão dos resíduos sólidos e dar visibilidade ao trabalho desde sua base da cadeia de reciclagem até a destinação final ambientalmente adequada.

No município de Criciúma - SC (Figura 1), a coleta seletiva é realizada por empresa terceirizada contratada pela prefeitura, a qual encaminha os resíduos sólidos recicláveis para empreendimentos de economia solidária, cooperativa (CTMAR) e associação (ACRICA) de catadores de materiais recicláveis. A coleta também é realizada por catadores autônomos de maneira informal. Ambos vendem os materiais recicláveis triados para intercessores pequenos e médios intermediários, os quais realizam a compra e a venda de papel, plástico, metal e outros materiais reaproveitáveis. Posteriormente, esses materiais são comercializados a outros intermediários de mesmo porte e nível ou para empresas recicladoras. 
Figura 1 - Localização do Município de Criciúma - SC
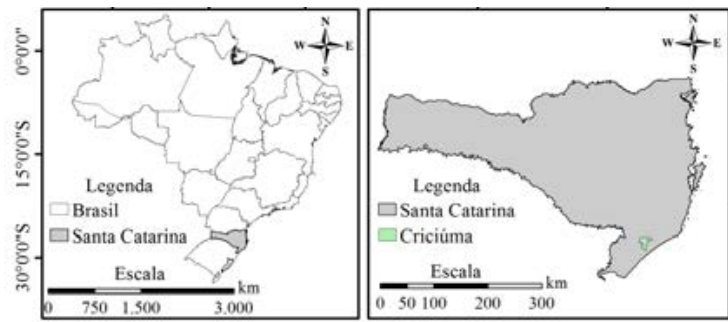

Fonte: Elaborada pelos autores, 2017

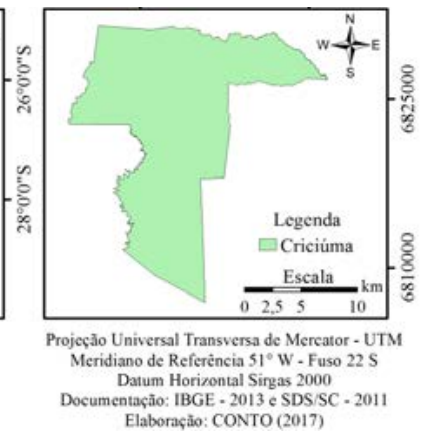

O mapeamento da cadeia de reciclagem do município de Criciúma e região sul catarinense, iniciado no segundo semestre de 2016, tem como objetivo identificar as diferentes classes e categorias de intermediários existentes no processo, isto é, as empresas que comercializam materiais recicláveis, e reconhecer as etapas e elos da cadeia da reciclagem, desde a geração dos resíduos sólidos até a fase de recuperação e transformação dos materiais em novos produtos. Tem como meta complementar realizar um estudo das relações estabelecidas entre os diferentes atores pertencentes à cadeia de reciclagem nas etapas de comercialização entre catadores, intermediários e indústrias de reciclagem.

O produto final do trabalho objetiva desenvolver um mapeamento georreferenciado das organizações de empreendimentos de economia solidária, associações e cooperativas de catadores; de sucateiros intermediários de materiais recicláveis nos diferentes níveis de participação na cadeia de reciclagem; e das empresas receptoras e transformadoras destes materiais.

\section{REVISÃo TEÓRICA}

Conforme a Lei 12.305/2010, a gestão integrada de resíduos sólidos é definida como o 
conjunto de ações voltadas para a busca de soluções para os resíduos sólidos, de forma a considerar as dimensões política, econômica, ambiental, cultural e social, com controle social e sob a premissa do desenvolvimento sustentável (BRASIL, 2010, Capítulo II, Artigo 3ㅇ, Inciso XI).

Segundo Jacobi (2006), a coleta seletiva consiste na separação na fonte geradora de materiais que podem ser reaproveitados ou reciclados e se configura em uma das ações que compõem um sistema de gerenciamento integrado de resíduos sólidos domiciliares. A Política Nacional de Resíduos Sólidos concebe coleta seletiva como "coleta de resíduos sólidos previamente segregados conforme sua constituição ou composição" (BRASIL, 2010, Capítulo II, Artigo 3ㅇ, Inciso V).

No entanto, para que os materiais pós-consumo, tais como são gerados nos domicílios, transformem-se em matérias-primas para as indústrias de transformação (reciclagem), é necessário que esses materiais sejam separados e segregados na fonte geradora, coletados seletivamente, triados, beneficiados e comercializados como insumos, formando o que é denominado de cadeia da reciclagem (RUTKOWSKI; VARELLA; CAMPOS, 2014).

A reciclagem pode ser entendida como "um procedimento industrial de reaproveitamento da matéria prima para a produção de novos produtos (similares ou não)" (EIGENHEER; FERREIRA; ADLER, 2005).

$A$ realidade brasileira frente à reciclagem não difere muito da enfrentada em toda a América Latina, segundo a Fundação Avina (2012):

Em toda a América Latina, os recicladores de resíduos são protagonistas e figuras fundamentais no processo de reciclagem. Entretanto, em sua maioria, eles carecem de estrutura de organização, reconhecimento formal e direitos legais, embora graças a sua determinação e ao poder da união, a situação tenha começado a mudar em seu favor. 
Na base do sistema da coleta seletiva no Brasil, estão os catadores de materiais recicláveis que realizam essa atividade, na maioria dos casos informal, sem o devido apoio dos órgãos públicos responsáveis pela gestão e gerenciamento de resíduos sólidos e pelos principais beneficiários da cadeia da reciclagem que são os sucateiros, intermediários e as indústrias de reciclagem (CONCEIÇÃO, 2005).

A base da cadeia de reciclagem formada pelo catador de material reciclável ou sucata ou vasilhame é definida na Classificação Brasileira de Ocupações como sendo composta por trabalhadores da coleta e seleção de material reciclável são responsáveis por coletar material reciclável e reaproveitável, vender e selecionar material coletado, preparar o material para expedição, realizar manutenção do ambiente e equipamentos de trabalho, divulgar o trabalho de reciclagem, administrar o trabalho e trabalhar com segurança (BRASIL/MTE, 2002).

A cadeia de reciclagem consiste nas relações existentes entre os atores do processo de reciclagem, desde a catação dos materiais recicláveis até processamento final na indústria. Segundo a Lei n. 12.305, de 2010, a reciclagem é definida como:

Processo de transformação dos resíduos sólidos que envolve a alteração de suas propriedades físicas, físico-químicas ou biológicas, com vistas à transformação em insumos ou novos produtos, observadas as condições e os padrões estabelecidos pelos órgãos competentes do Sisnama e, se couber, do SNVS e do SUASA (BRASIL, 2010, Capítulo II, Artigo 3ㅇ, Inciso XIV).

Ao efetuar o estudo da reciclagem de resíduos sólidos urbanos no Brasil com vistas a superar desafios e oportunidades para ampliação (RUTKOWSKI; VARELLA; CAMPOS, 2014), subdividiram em três categorias básicas os atores pertencentes à cadeia produtiva de recuperação de materiais recicláveis pós-consumo: 
a. Empreendimentos recuperadores de materiais recicláveis (REC) são aqueles que recuperam o material reciclável das sobras do consumo jogados no lixo. Com diferentes formas e condições de atuação, há dois tipos. Tipo 1 (REC T1): aqueles empreendimentos que fazem coleta junto aos geradores (grandes geradores ou domésticos) e nas ruas e avenidas com execução da primeira triagem. Composto por Associações e Cooperativas de catadores materiais recicláveis (ACs), os catadores autônomos, independentes e inclui-se também as poucas unidades de triagem municipais existentes no país; Tipo 2 (REC T2): aqueles que adquirem material reciclável semisselecionado e assim o comercializam; podem também executar uma triagem secundária, por exemplo, a classificação do material feita com o papel nos aparistas. Compreendem os chamados atravessadores ou intermediários e são conhecidos como ferros velhos, depósitos, sucateiros, aparistas (RUTKOWSKI; VARELLA; CAMPOS, 2014);

b. empreendimentos revalorizadores (REV) de materiais recicláveis: empresas que efetuam um passo intermediário, transformando os materiais retirados do lixo em matéria-prima para outra indústria. São, por exemplo, as indústrias produtoras de pellets/ grãos e flocos/ flakes a partir de plásticos reciclados, fábricas produtoras de bobinas de papel que alimentam a indústria de embalagens de papel. Esses empreendimentos produzem matéria-prima secundária para a indústria de plástico e de papel, e podem ou não fazer triagem (RUTKOWSKI; VARELLA; CAMPOS, 2014);

c. empreendimentos transformadores (TRANS) de matéria-prima reciclada: indústrias que fabricam produtos de papel e plástico a partir de matéria prima produzida com material revalorizado em forma de grãos ou flocos, para o caso do plástico ou recuperado e reinserido na cadeia produtiva original, como no caso do papel. (RUTKOWSKI; VARELLA; CAMPOS, 2014). 
De acordo com Ribeiro e Lima (2000), em países onde o custo da mão de obra é maior, as empresas de limpeza urbana investem cada vez mais em tecnologia na busca de soluções econômicas e eficientes que garantam a qualidade dos serviços de coleta, transporte, tratamento e destino final de resíduos sólidos, sendo estritamente pela colaboração efetiva da população atendida pelo sistema.

Os países que mais buscam soluções sustentáveis, onde a reciclagem é fator importante na redução do volume de resíduos sólidos urbanos são Alemanha, Japão, Holanda, Canadá e os EUA. Ao longo da última década, os governos europeus incrementaram várias normas para reduzir o impacto ambiental causado pelas embalagens, através da legislação (EIGENHEER, 1998 apud RIBEIRO; LIMA, 2000).

As normas adotadas por esses países estão relacionadas principalmente a regras para depósito em diferentes tipos de "containers", sobretudo fábricas de bebidas; a proibição de embalagens com materiais que causem danos ao meio ambiente, principalmente PVC; e a impressão selos na embalagem, indicando que o material é reciclável (RIBEIRO; LIMA, 2000).

\section{METODOLOGIA}

O estudo da cadeia cinza da reciclagem concentrou-se em uma etapa de pesquisa: exploratória, com base em revisão bibliográfica para familiarizar-se com o tema referente à cadeia de reciclagem e ao papel desempenhado por cada ator, o que possibilitou a construção de hipóteses de funcionamento dos enlaces entre os diferentes participantes na recuperação pós-consumo e descarte de materiais recicláveis.

A fase exploratória buscou explicitar o problema por meio de um levantamento bibliográfico (GIL, 2008), em artigos e bases cientificas sobre 
os atores participantes da cadeia de reciclagem. Após a primeira aproximação (pesquisa exploratória), realizou-se uma etapa descritiva como o objetivo primordial da exposição das características das inter-relações estabelecidas desde a base da cadeia de reciclagem, o catador individual autônomo ou organizado em empreendimentos de economia solidária, até culminar com empresas de transformação de materiais recicláveis no território de Criciúma - SC.

Quanto ao delineamento dos procedimentos técnicos metodológicos para efetivamente conduzir a pesquisa com coleta de dados, após a fase inicial com subsídios e aportes em estudos anteriores que forneceram um norte teórico efetuou-se o planejamento da pesquisa de campo com elaboração de instrumentos de coleta de dados. A realização do mapeamento da cadeia de pós-consumo foi efetuada mediante pesquisa a campo com coleta de dados primários e visitas in loco às empresas pertencentes à cadeia de reciclagem do município de Criciúma SC, desde intermediários de nível 1 até empresas recicladoras, sendo elas especializadas em um ou mais tipos de materiais.

O percurso da pesquisa foi definido com base em observações efetuadas em trechos identificados primeiro com andar de bicicleta. Após definidos os rumos, a equipe de investigação efetuou visitas para entrevistas semiestruturadas e prospecção de pontos de localização de cada empreendimento. As empresas visitadas atuam na cadeia de reciclagem principalmente com papel, plástico e/ou metal. O vidro, embora retornável e $100 \%$ com potencial de reciclagem, não é recuperado para reinserção em cadeias produtivas na região, já que inexistem empresas que trabalhem com este material.

Em cada visita, foi aplicado um formulário desenvolvido pela equipe, materializado geralmente por meio de uma entrevista semiestruturada para coletar informações detalhadas da organização, incluindo perguntas abertas e fechadas. Nele, constam questões para identificação da empresa, infraestrutura, número de funcionários, tipos de materiais que trabalham o fluxo mensal em toneladas e preços de compra e venda de cada material, as empresas para quem vendem e as de quem compram, 
e por fim informações adicionais e as principais dificuldades enfrentadas atualmente. Além do formulário, foram realizados registros fotográficos, com autorização dos proprietários, dos materiais e da infraestrutura do local.

Com os dados coletados, realizaram-se análise das características identificadas em comum nos empreendimentos, classificando-os, de acordo com a metodologia desenvolvida por Aquino, Castilho e Pires (2009), e por Conceição et al. (2016) em intermediário nível 1 (pequeno sucateiro), intermediário nível 2 ou reciclador distribuidor (médio sucateiro), intermediário nível 3 - reciclador -beneficiador ${ }^{2}$ (grande sucateiro) ou reciclador transformador ${ }^{3}$, e por caso se diferencie de todas as classes citadas, o empreendimento foi analisado e, então, uma nova classificação foi criada. Adotou-se a classificação proposta de atuação na cadeia de reciclagem conforme papel desempenhado nas respectivas etapas a identificação sugerida por Rutkowski, Varella e Campos (2014).

Utilizando as informações coletadas, confeccionou-se um mapa utilizando o Google Maps, no qual se escolhe o ícone que representa a classe do referido empreendimento. Em cada um deles, foram incluídas informações gerais, endereço, telefone de contato e algumas fotos.

Observando os dados coletados e o mapa confeccionado com a utilização da ferramenta do Google Maps, fez-se inicialmente a regionalização e mapeamento de todos os atores identificados da cadeia de reciclagem, posteriormente a hierarquização deles e, por fim, a classificação quanto à tipologia dos materiais que esses trabalham.

\section{RESULTADOS}

Para socializar o resultado, foi utilizada a base de dados disponíveis no Google Maps, que pode ser descrito como um software de pesquisa e visualização gratuito desenvolvido pela empresa estadunidense Google. Ele fornece imagens de satélites e mapas de todas as partes da superfície da terra. Tanto o Google Maps como o Google Earth apresen- 
tam o mesmo objetivo que é a visualização do espaço geográfico e suas variáveis paisagens naturais e humanas, no entanto a principal diferença é que o Google Maps não apresenta as imagens de forma tridimensional como o segundo aplicativo (MOREIRA, 2008).

O acesso ao Google Maps se dá por qualquer navegador, a exemplo do Mozilla Firefox, Internet Explorer, Google Chrome e outros existentes. Ao nos conectarmos à internet e solicitarmos o endereço: http:// Maps.google.com.br, abre-se uma página inicial, na qual há espaço para digitar o local que se deseja conhecer.

Pela facilidade de acesso em qualquer navegador à pesquisa da cadeia cinza da cadeia de reciclagem com formação de base de dados em construção, é disponibilizado um link para acesso e socialização dos resultados de pesquisa em execução dentro do projeto de Extensão Coleta Seletiva Solidária da Unesc, que reflete de forma indissociável no fazer e ensinar interdisciplinar da Engenharia Ambiental e Sanitária, Psicologia, Direito, Nutrição e Sociologia.

O mapa está em fase de criação e pode ser acessado em: https://drive.google.com/open?id=1ibG-WfBSLpPMJL8Zxgzgvn4ZSCI\&us$\mathrm{p}=$ sharing

Os símbolos têm significados. Pontos em azul indicam empresas intermediárias da cadeia de reciclagem que atuam com papel, papelão e embalagem longa vida (Tetra $\mathrm{Pack}^{\circledR}$ ); círculos com letra P indicam empresas intermediárias da cadeia de reciclagem de plásticos; círculos em amarelo indicam empresas que atuam com metais. As associações e cooperativas de catadores estão indicadas com símbolos de mãos postas com fundo verde. Também há uma simbologia para as empresas que efetivamente transformam os produtos e finalizam a cadeia de reciclagem reintroduzindo no mercado novos materiais assinalados com a marca da reciclagem e as respectivas cores de cada material conforme resolução CONAMA n. 275/2001 (BRASIL, 2001). Apenas para registro e para conhecimento, foram indicados também os locais de deposição de rejeitos, os aterros sanitários. 
Em cada ponto, há informações complementares como telefone de contato, link de site, ou página de rede social e área de atuação, assim como fotos dos respectivos locais.

A base de dados mapa elaborada empregando o Google Maps (Figura 2) possui nove diferentes classes diferenciadas pelo símbolo e cor escolhidos, conforme suas determinadas características (tipo de empreendimento, material que trabalha e classe que pertence à cadeia de reciclagem). O mapeamento inclui catadores autônomos, cooperativas ou associações, intermediários de papel, plástico ou metal, empresas recicladoras de plástico ou papel, além de lixões e aterros sanitários.

Figura 2 - Base de dados preliminar da cadeia de reciclagem de Criciúma e região

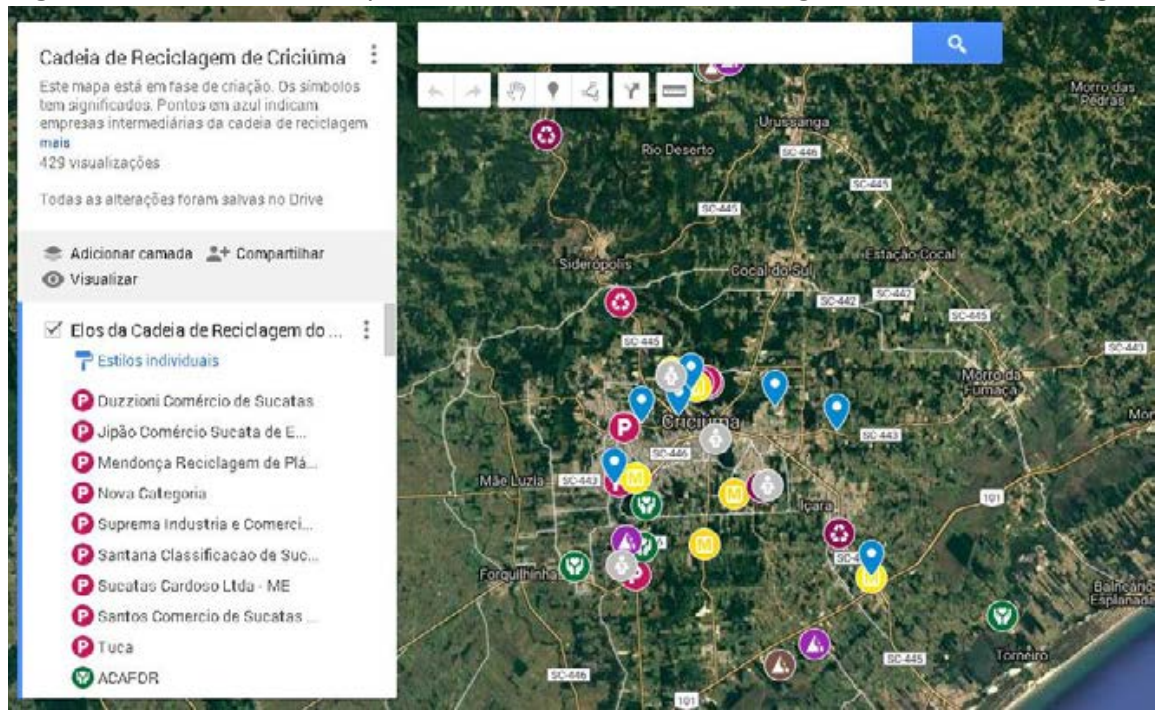

Fonte: Google Maps, 2017.

Os atores e labores da cadeia cinza de reciclagem possuem papéis distintos, porém interligados. Atuam para fechar os elos que fazem retornar as sobras de diferentes materiais recicláveis, embalagens em geral que passam de objeto de desejo para a satisfação da necessidade de 
consumo a classificação de descartáveis, passíveis de deposição em contentores e lixeiras para coleta convencional ou colocadas para a recolha diferenciada em programas de coleta seletiva.

Ao final da pesquisa in loco, foram visitados o total de 23 empreendimentos, os quais foram classificados conforme seu nível dentro da cadeia de reciclagem e o tipo material que trabalha (Tabela 1) e distribuídos espacialmente na representação cartográfica (Figura 3).

Tabela 1 - Classificação dos empreendimentos visitados

\begin{tabular}{|c|c|c|c|c|c|}
\hline Classes & Terminologia & Metal & Papel & Plástico & Multimateriais \\
\hline Catador autônomo & $\begin{array}{c}\text { Catador triador }^{3} \\
\text { Recuperadores tipo } 1^{4}\end{array}$ & 0 & 0 & 0 & 1 \\
\hline Catador organizado & $\begin{array}{c}\text { Catador triador } \\
\text { Recuperadores tipo } 1^{4}\end{array}$ & 0 & 0 & 0 & 2 \\
\hline Intermediário nível $1^{1}$ & $\begin{array}{c}\text { Reciclador- } \\
\text { classificador/distribuidor } \\
\text { Recuperadores tipo } 2^{4}\end{array}$ & 1 & 0 & 1 & 3 \\
\hline Intermediário nível $2^{1}$ & $\begin{array}{l}\text { Reciclador distribuidor }{ }^{2} \\
\text { Revalorizadores }^{4}\end{array}$ & 0 & 1 & 2 & 5 \\
\hline Intermediário nível $3^{1}$ & $\begin{array}{l}\text { Reciclador-beneficiador }{ }^{2} \\
\text { Revalorizadores }^{4}\end{array}$ & 1 & 1 & 2 & 1 \\
\hline
\end{tabular}

Fonte: Adaptada de AQUINO; CASTILHOS; PIRES, 2009ㅜ; CONCEIÇÃO et al. 2016²; RUTKOWSKI; VARELLA; CAMPOS, 2014³). 
Figura 3 - Distribuição espacial no território urbano de Criciúma dos participantes dos elos da cadeia de reciclagem

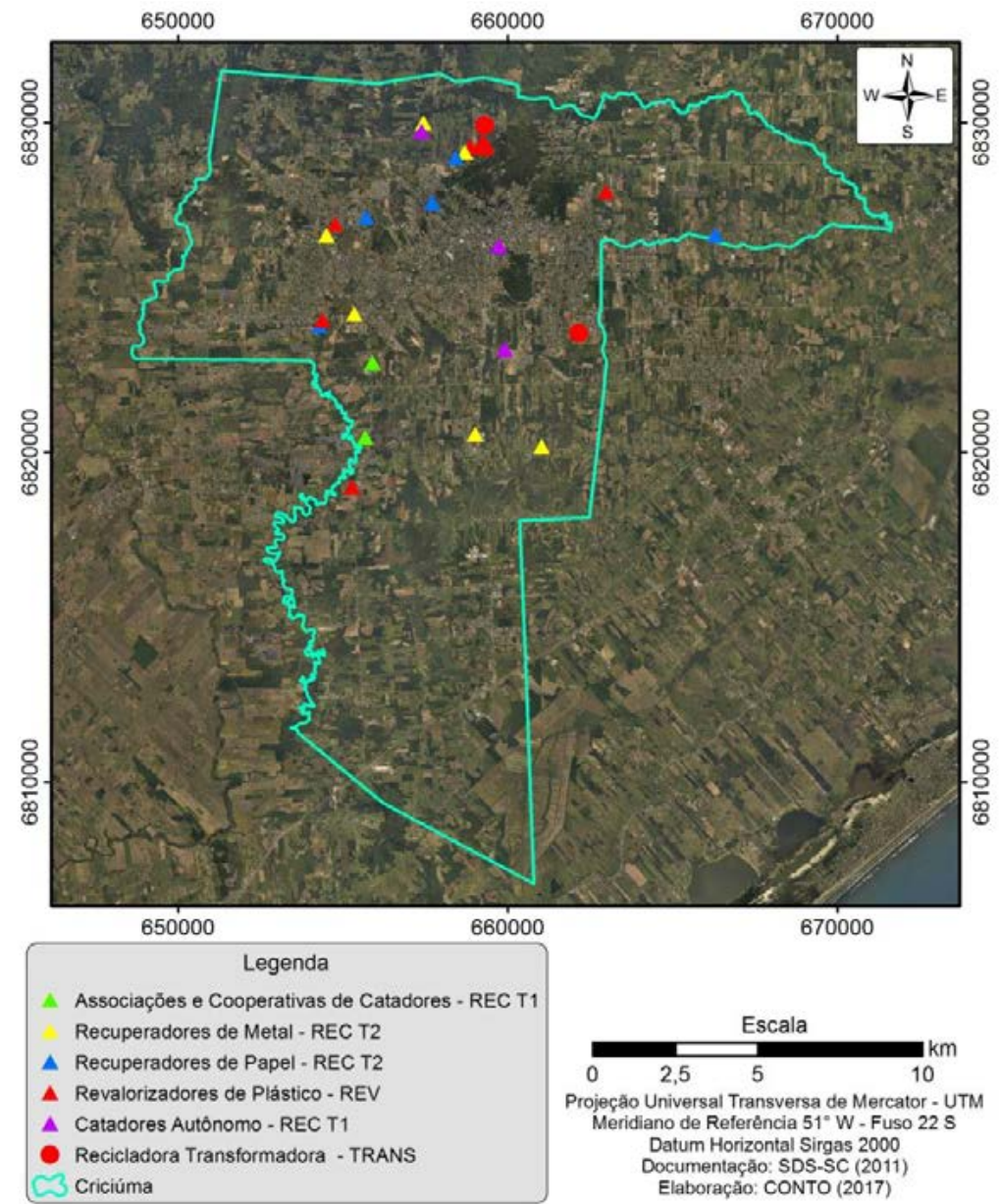

Fonte: Elaborada pelos autores, 2017.

Os atores da cadeia de reciclagem são divididos em três grandes grupos: recuperadores (reciclador-classificador/distribuidor); revalorizadores (reciclador distribuidor); e transformadores (Recicladorbeneficiador) (Figura 4), em que o último nível refere-se àqueles em- 
preendimentos que realizam processos de transformação do material reciclável, seja para ser utilizado como matéria-prima para a indústria, seja como produto final para o consumidor, e o segundo grupo diz respeito aos atores que comercializam os resíduos sólidos. O primeiro nível, com duas subdivisões, inclui os catadores autônomos (catador triador) e intermediários sucateiros, ferros velhos, aparistas intermediários (sendo identificados como nível 1, 2 e 3, respectivamente).

Existe uma hierarquia dentro da cadeia de reciclagem, na qual, quanto maior o nível, maior é a relevância, já que os preços de comercialização são definidos pelos intermediários de nível superior e indústrias. Isso acontece porque esses possuem melhores condições de infraestrutura, o que reflete em maior espaço para armazenamento do material por um longo prazo sem prejudicar sua qualidade. Essa possibilidade faz com que o empreendedor decida o melhor momento para venda, agregando mais valor e confiança do comprador final (reciclador e/ou indústria).

Figura 4 - Hierarquia da cadeia de reciclagem em Criciúma e região

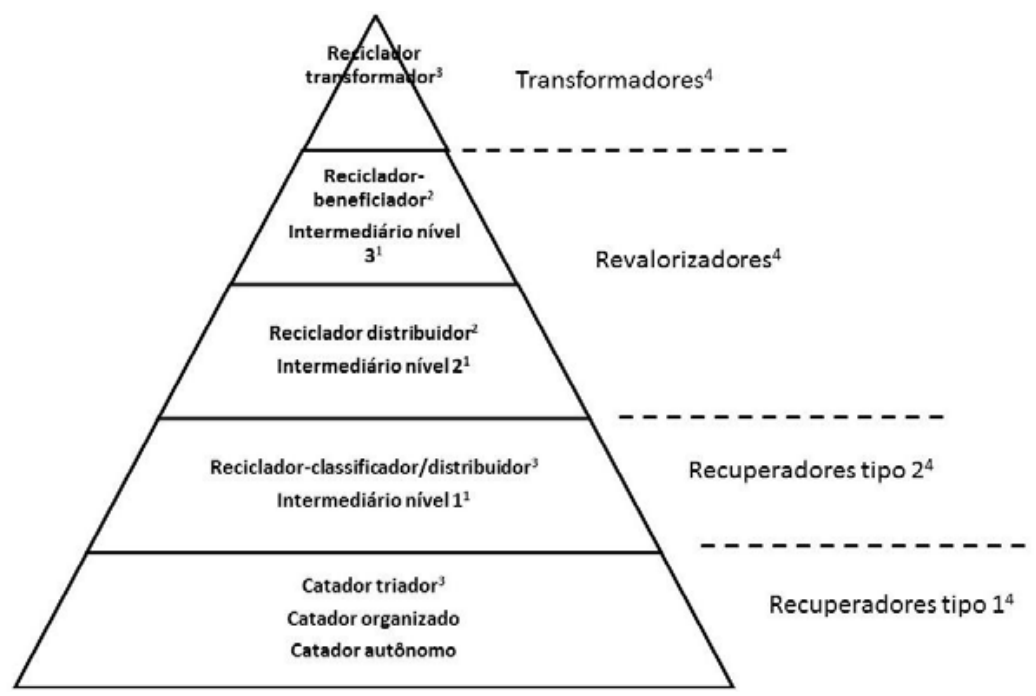

Fonte: Adaptado de (AQUINO; CASTILHOS; PIRES, 2009ㅜ; CONCEIÇÃO et al. 2016² ; RUTKOWSKI; VARELLA; CAMPOS, $2014^{3}$ ). 
Os critérios para a classificação dos empreendimentos nos diferentes níveis da cadeia de reciclagem foram o porte deles, a infraestrutura disponível, os equipamentos utilizados, os materiais coletados, recebidos e comercializados, além das relações de (inter)dependência entre os elos da cadeia de reciclagem.

Para levantamento dos dados e caracterização dos níveis da cadeia de recilcagem, foi aplicado questionário com 23 atores da cadeia, classificando-os posteriormente como catadores autônomos ou organizados, intermediários nível 1, 2 e 3 ou indústria recicladora (Gráfico 1). Durante a pesquisa, identificou-se um empreendimento que não se enquadrou em nenhum dos níveis de intermediários ou como catador, sendo nomeado como "outra categoria". A principal característica desse empreendimento é trabalhar como tercerizado para um intermediário, o qual é responsável por triar um determinado tipo de material.

Gráfico 1 - Classificação dos empreendimentos conforme posição na cadeia de reciclagem

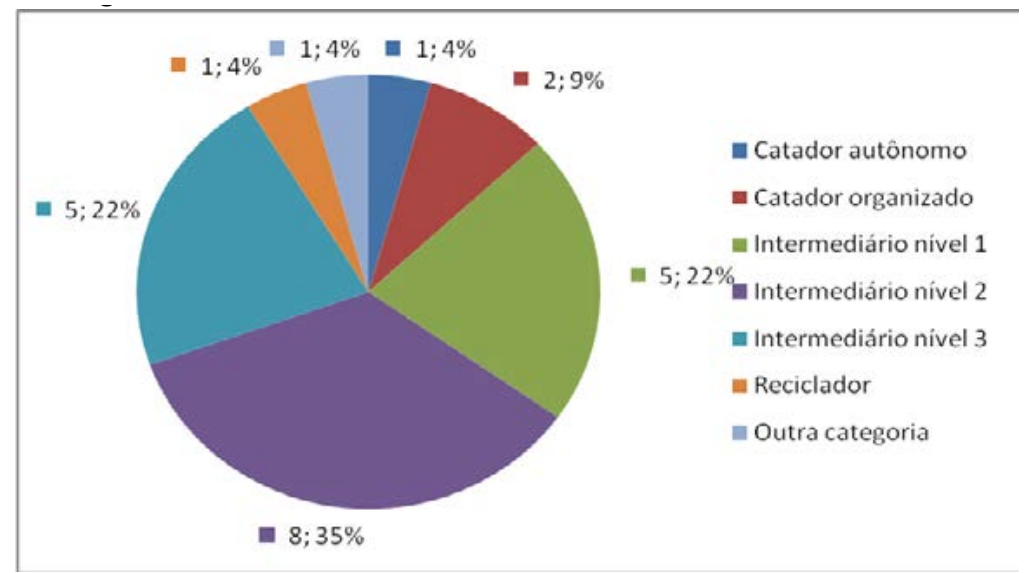

Fonte: Elaborado pelos autores, 2017.

Ao final da pesquisa, detectou-se que a maior parte dos empreendimentos visitados, 52\%, trabalham com multimateriais (Gráfico 2), 
ou seja, compram e comercializam mais de um tipo de material reciclável (geralmente papel, plástico e metal). Essa característica se reflete em outros empreendimentos do município de Criciúma e região, e isso se dá devido à falta de segurança financeira em depender exclusivamente da venda de um tipo de material, à carência de garantia de ter compradores para esse e de possuir quantidade suficiente de material de qualidade para comercialização, já que a maior parte dos intermediários nível 1 e 2 recebem material de catadores o qual costuma possuir baixa qualidade.

Gráfico 2 - Classificação dos empreendimentos conforme tipo de material que trabalha

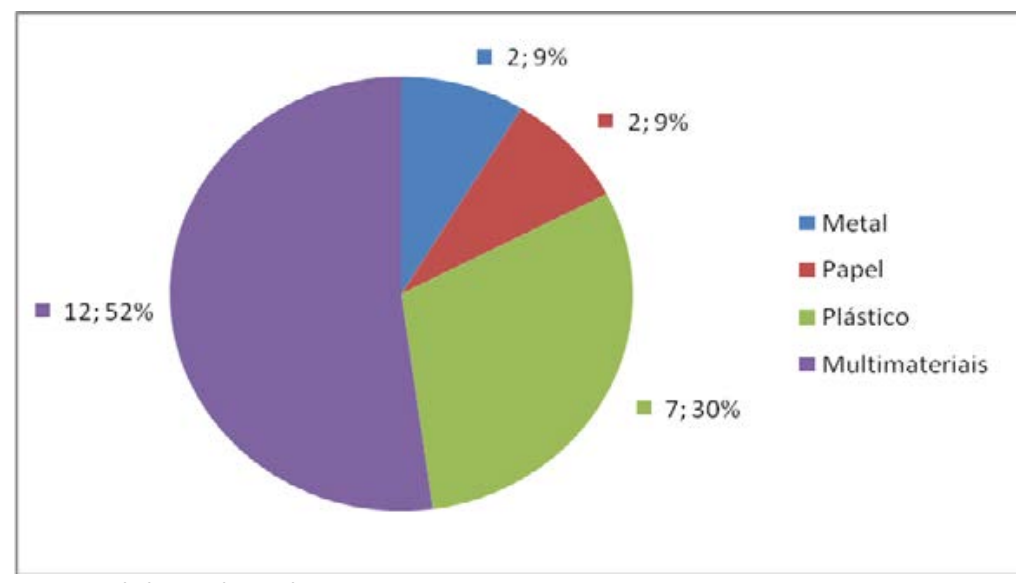

Fonte: Elaborado pelos autores, 2017.

Além da distinção quanto ao tipo de material que trabalham, os atores são classificados em catadores, intermediários, sendo esses subdivididos segundo suas particularidades em nível 1, 2 e 3, e empresas recicladoras. O fluxograma (Figura 5) demonstra a interação destes atores e a logística dos materiais recicláveis desde que descartados, seja após o consumo ou como resíduo da indústria, passando pelos diferentes níveis da cadeia de reciclagem, até serem então reciclados ou destinados ao aterro sanitário. 
Figura 5 - Atores, enlaces, elos da cadeia de reciclagem e principais processos que realizam em Criciúma - SC

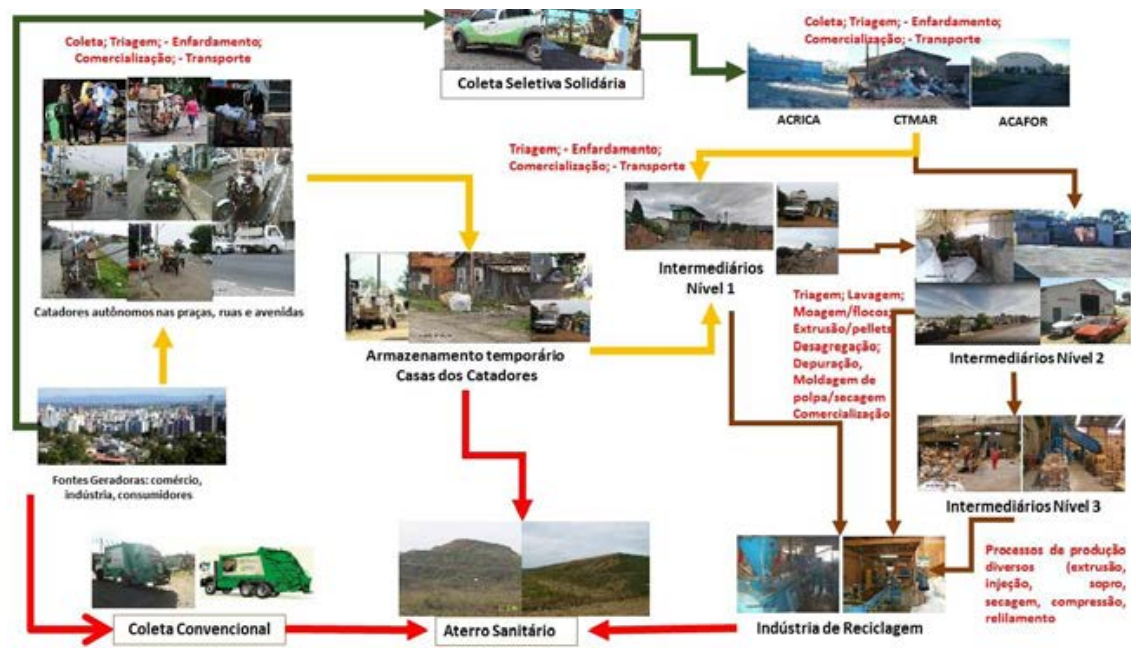

Fonte: Elaborada pelos autores, 2017.

O termo cadeia cinza da reciclagem é uma expressão empregada para caracterizar os processos paralelos estabelecidos entre os atores da cadeia produtiva de reciclagem pós-consumo, desde a coleta e catação pelo catador autônomo ou cooperado até a comercialização com os transformadores - recicladores.

A Figura 5 reproduz os caminhos percorridos pelos materiais recicláveis dentro dos limites do território de Criciúma, com as operações de classificação, processamento, comercialização e transformação para retorno ao ciclo do consumo.

Considerando que o consumidor de Criciúma é o elo à montante da cadeia de reciclagem, é ele quem inicia o processo descartando (in) adequadamente os resíduos recicláveis que são a matéria-prima bruta. Esses resíduos são recolhidos, em grande parte, pela empresa terceirizada que efetua tanto a coleta convencional como a seletiva. Os resíduos recolhidos pela empresa terceirizada são entregues em duas unidades de triagem e separação, empreendimentos de economia solidária, associação 
e cooperativa de catadores que efetuam a triagem comercializando para intermediários recuperadores e revalorizadores da cidade e, em alguns casos, diretamente para transformadores/recicladores.

Os catadores independentes, parcela significativa de atores da cadeia cinza da reciclagem, atuam nas praças, ruas e avenidas que exercem a coleta, improvisando meios de transporte e separação, e comercializam com recuperadores tipo 2 - classificadores/distribuidores locais, que, por sua vez, comercializam com intermediários revalorizadores de maior porte locais e regionais até obterem escala para a venda às empresas transformadoras recicladoras na região sul catarinense (plástico), e em outras regiões do Estado onde estão estabelecidas empresas de reciclagem de papel e papelão. Há casos de transporte para empresas transformadoras de outros estados, por exemplo, na cadeia de reciclagem de embalagens multicamadas e alumínio.

Os resíduos recicláveis, depois de dispostos nas lixeiras, são coletados pela empresa terceirizada que realiza a coleta seletiva municipal, a qual direciona os resíduos para a Associação Criciumense de Catadores (ACRICA) e para a Cooperativa de Trabalhadores de Materiais Recicláveis de Criciúma (CTMAR), as quais realizam separação e triagem. Em seguida, enfardam, sendo comercializados. Ocorre também a coleta desordenada por catadores autônomos que trabalham de maneira informal, coletando nas ruas ou de algum fornecedor, na maioria das vezes em condições precárias, comercializando a granel, solto, acondicionando eventualmente em bags. Os materiais recicláveis são separados em poucas categorias. Ambos vendem para intermediários nível 1 ou 2 também denominados recuperadores.

Os intermediários de nível 1 - recuperadores recebem os resíduos e os triam novamente, retirando o rejeito e outros materiais, enfardam e os comercializam. De acordo com os dados coletados, possuem mais problemas quanto à infraestrutura, fiscalização, falta de incentivo municipal e recursos financeiros limitados, já que esses compram, na maioria das vezes, diretamente de catadores autônomos, e o material recebido possui uma grande quantidade de rejeito misturado. 
Os intermediários de nível 2 são recuperadores, pois compram resíduos de cooperativas, associações e pequenos sucateiros e vendem para intermediários nível 3 (Recicladores/Transformadores). Os recuperadores realizam também a triagem, enfardamento e comercialização. Esses possuem condições melhores que o nível anterior, porém ainda encontram dificuldades quanto às questões de fiscalização, falta de incentivo e rejeitos misturados ao material comprado.

Já os intermediários de nível 3 são designados também como revalorizadores, pois, além das etapas de triagem e enfardamento, algumas vezes realizam uma etapa da reciclagem, como a moagem. Possuem maior domínio sobre o mercado e acabam determinando o preço de compra de todos os demais níveis, adquirem materiais de intermediários de nível 2 (recuperadores) e diretamente de grandes empresas e redes de supermercados, e vendem para empresas recicladoras/transformadoras. A infraestrutura é avançada, sentem poucos os efeitos da crise econômica e não relatam dificuldades quanto à fiscalização ou falta de incentivo.

As empresas recicladoras/transformadoras possuem um mercado de compra amplo e pequeno número de concorrentes na região, portanto possuem nenhuma, ou pouca dificuldade, quando comparadas aos intermediários e demais empreendimentos pertencentes à cadeia de reciclagem.

Ainda quanto às diferenças identificadas na pesquisa a campo, os intermediários de metal são os que menos perceberam interferências da crise econômica enfrentada pelo país, já que o preço de comercialização desse material é determinado conforme variação cambial do dólar.

\section{DISCUSSÃO}

O artigo 8 o da Lei n. 12.305/2010, que institui a Política Nacional dos Resíduos Sólidos, traz o incentivo à criação e ao desenvolvimento de cooperativas ou de outras formas de associação de catadores de materiais reutilizáveis e recicláveis como um instrumento dessa política pública. 
Dessa forma, é indispensável a organização dos catadores autônomos de Criciúma e região em unidades de separação e triagem sob o formato de associação ou cooperativa, conforme previsto na PNRS, a fim de promover maior segurança a esses trabalhadores e possibilidade de negociação com os compradores dos diversos materiais recicláveis.

As poucas organizações de catadores existentes em Criciúma ainda não trabalham efetivamente como uma cooperativa ou associação. Existem problemas na gestão administrativa desses empreendimentos, faltam treinamentos e capacitações para os associados e há uma alta rotatividade de trabalhadores, o que reflete em um trabalho descontínuo e com baixa qualidade na separação correta dos resíduos. Essas características traduzem a baixa qualidade dos materiais relatada pelos intermediários de todos os níveis e indústria recicladora.

No entanto, embora existam falhas dentro dos empreendimentos de economia solidária, a principal origem desse problema de os materiais apresentarem baixa qualidade está na deficiência ou falta de ações e programas ambientais para conscientização da população quanto à importância da segregação dos resíduos recicláveis, à forma que deve ser realizada e quando, qual horário realmente ocorre a coleta seletiva nos bairros do município.

A grande maioria dos empreendimentos visitados, desde organização de catadores até intermediários nível 2, apresentam alguma desconformidade legal, seja com o órgão ambiental (licenciamento) ou com a prefeitura municipal (alvará). O não pagamento de impostos, do alvará de funcionamento ou licenciamento ambiental é cômodo aos empreendimentos, já que a ausência de registro e o não recolhimento de taxas e impostos aumentam seus lucros, no entanto não garante que esses não estão prejudicando o meio ambiente ou os trabalhadores contratados ou associados (precarização das condições de trabalho e ausência da previdência social, SUS). Sendo assim, fazem-se necessários um maior controle e fiscalização tanto tributários quanto ambiental e trabalhistas, a fim de monitorar se os empreendimentos se encontram em conformidade com os requisitos legais. 
As diferenças identificadas entre os níveis da cadeia de reciclagem se dão por uma série de motivos. Os empreendedores com maior nível de instrução e/ou experiência costumam ser classificados nos níveis mais altos (revalorizadores ou transformadores), devido à sua maior habilidade de negociação e consolidação dentro do mercado dos resíduos sólidos recicláveis. Como regra, esses costumam possuir melhores condições de infraestrutura (galpões, equipamentos e veículos para transporte), são mais rigorosos na qualidade do material recebido dos fornecedores (recuperadores) e trabalham com volumes muito maiores de resíduos.

Os empreendimentos de nível mais baixo, principalmente catadores e pequenos sucateiros, habitualmente possuem condições piores de infraestrutura, o que prejudica o armazenamento e impossibilita a estocagem por um longo prazo de tempo. Esses catam na rua (catadores autônomos), recebem material provenientes da coleta seletiva (catadores organizados) ou compram o material desses catadores (intermediários nível 1), material o qual apresenta qualidade ruim devido ao grande percentual de impurezas, umidade e rejeito, desvalorizando o resíduo.

O plástico por ser inerte é muito comercializado na região de Criciúma, já que não perde qualidade quando exposto à chuva ou ao sol. Sendo assim, é de mais fácil destinação e reinserção na cadeia de reciclagem, diferente do papel, uma vez que diversos agentes químicos, físicos e biológicos, naturais ou antrópicos, prejudicam sua qualidade, perdendo valor ou até mesmo inviabilizando sua comercialização. O metal, por sua vez, também apresenta um mercado amplo, sendo a venda realizada na maior parte das vezes por catadores autônomos, que catam os materiais de maior valor (embalagens de alumínio) e comercializam. O metal, quando trabalhado em grande volume, demanda grande espaço e maior segurança, pois o maior valor que esse apresenta costumeiramente acontecem tentativas ou casos de furtos ou desvios de materiais até mesmo nas organizações da base da cadeia de reciclagem como a associação ou cooperativa de catadores. 


\section{CONSIDERAÇÕES FINAIS}

A cadeia cinza de reciclagem é de certa complexidade e envolve uma série de questões que ditam os preços de comercialização, os quais interferem diretamente na sustentabilidade física e financeira dos empreendimentos que pertencem a ela. A quantidade e qualidade dos materiais recicláveis comercializados são os principais fatores limitantes.

A identificação e mapeamento da população catadora que atua de forma autônoma e independente se faz necessária nos municípios, em especial em Criciúma e região, para uma melhor identificação e reconhecimento da horda de catadores invisíveis que perambulam por vielas, ruas e avenidas na busca de sobras do consumo e que tentam, dessa forma, não ter suas vidas desperdiçadas, mas que ficam, muitas vezes, à mercê dos intermediários da cadeia de reciclagem, bem como para que seja iniciada a discussão acerca dos direitos desses e dessas trabalhadoras, que são assegurados pela política pública federal, Lei 12.305/2010.

De acordo com a Política Nacional dos Resíduos Sólidos (PNRS), está previsto para os municípios onde há presença de catadores e catadoras que eles sejam organizados em unidades de separação e triagem sob o formato de associação ou cooperativa. Esse pré-requisito da PNRS pode ser alcançado no nível municipal e regional mediante um olhar interdisciplinar, intersetorial e intersecretarias da administração pública porque o cidadão e a cidadã, catador e catadora, necessitam muito mais do que apenas o resultado da coleta seletiva que são os materiais recicláveis, mas, principalmente, o empoderamento, a formação, a capacitação para gerir e administrar empreendimentos de economia solidária. Além de olhar para o ser humano com suas necessidades psicossociais.

A metodologia desenvolvida para mapeamento da cadeia de reciclagem é um aperfeiçoamento dos trabalhos desenvolvidos por Aquino, Castilhos e Pires (2009), com o acréscimo de uma legenda ou ícone de identificação e georreferenciamento dos estabelecimentos da cadeia de reciclagem nos seus diferentes níveis, que permite acesso fácil 
da informação a qualquer cidadão que queira entregar voluntariamente materiais às cooperativas e associações, da mesma forma que possibilita para grandes geradores a doação para empreendimentos de economia solidária ou a comercialização a intermediários (recuperadores, revalorizadores e transformadores) da cadeia de reciclagem e também serve para os agentes públicos de controle e fiscalização tanto tributário quanto ambiental para monitorar se os empreendimentos que atuam na cadeia de reciclagem estão em conformidade com os requisitos legais.

Os empreendimentos que pertencem à cadeia de reciclagem em seus diferentes níveis atuam com um certo respeito velado a hierarquia presente, mas é uma atuação independente. Algumas dificuldades apontadas poderiam ser solucionadas se eles se organizassem em uma associação de empreendimentos da cadeia de reciclagem. Uma das ações que servem como indicador para coleta seletiva é o mapeamento desses empreendimentos, possibilitando o conhecimento da comunidade como um todo acerca da coleta seletiva, bem como do acompanhamento da execução do Plano Municipal de Resíduos Sólidos, que ainda não vigora na cidade.

A articulação dos setores e a visibilidade dada à questão da coleta seletiva, ainda muito problemática no município, suscitam o debate, acendem a discussão e, em contrapartida, tendem a oferecer melhores condições aos atores do trabalho de base da cadeia de reciclagem, a fim de minimizar perdas e agregar valor aos resíduos comercializados. No entanto, salienta-se a necessidade de maior capacitação, treinamento e preparo dos funcionários envolvidos em todo o processo para diminuir a quantidade de rejeito e materiais distintos associados, além de um maior investimento em educação ambiental para a comunidade participar efetivamente da coleta seletiva.

A cadeia cinza da reciclagem demonstra a falta de integração entre os agentes atores envolvidos no processo, desde a fragilidade dos trabalhos de sensibilização, mobilização social e educação ambiental para segregação na fonte geradora de materiais recicláveis, a permanente condição de precarização do trabalho de uma (in)certa população de 
catadoras e catadores autônomos que atuam de forma independente, a deficitária e precária infraestrutura existente nas unidades de separação e triagem do município e os elos estabelecidos a jusante onde a cooperação estabelecida nas interligações que possibilita a maximização do capital lucro, do ponto de vista empresarial.

Para superar essas quebras de elos da cadeia de reciclagem, é necessário implantar um sistema de informações (bando de dados) sobre reciclagem em Criciúma e região integrando os diferentes geradores de informação (Fundações Municipais de Meio Ambiente, FATMA, UNESC, UNIBAVE...), investir em infraestrutura adequada de separação e triagem com empreendimentos de economia solidária e inclusão social produtiva de catadores e catadoras em associações e cooperativas, implementar efetivamente a coleta seletiva conforme preconiza a Política Nacional de Resíduos Sólidos e executar campanhas permanentes de sensibilização e mobilização social para a separação e triagem de materiais recicláveis na fonte geradora.

\section{REFERÊNCIAS}

AQUINO, I. F.; CASTILHO JUNIOR, A. B.; PIRES, T. S. L. A organização em rede dos catadores de materiais recicláveis na cadeia produtiva reversa de pós-consumo da região da grande Florianópolis: uma alternativa de agregação de valor. Gestão \& Produção, [s.I.], FapUNIFESP (SciELO), v. 16, n. 1, p.15-24, mar. 2009. Disponível em: <http://www.scielo.br/pdf/gp/ v16n1/v16n1a03>. Acesso em: 10 jun. 2017.

BRASIL. Ministério do Trabalho e Emprego. Classificação Brasileira de Ocupações Cbo. Catador de Material Reciclável: Trabalhadores da coleta e seleção de material reciclável, 2002. Disponível em: <http://www. mtecbo.gov.br/cbosite/pages/pesquisas/BuscaPorTituloResultado.jsf>. Acesso em: 10 jun. 2017. 
BRASIL. CONSELHO NACIONAL DE MEIO AMBIENTE CONAMA, Resolução n. 275, de 25 de abril de 2001, do Conselho Nacional do Meio Ambiente - CONAMA. "Estabelece o código de cores para os diferentes tipos de resíduos, a ser adotado na identificação de coletores e transportadores, bem como nas campanhas informativas para a coleta seletiva"; Brasília, DF: publicada no Diário Oficial da União n. 117, p. 80. em 19/06/ jun. 2001; Brasília, DF. Disponível em: <http://www.mma.gov.br/port/conama/ legiabre.cfm?codlegi=273>. Acesso em: 12 ago. 2017.

BRASIL. Lei n. 12305, de 02 de agosto de 2010. Institui a Política Nacional de Resíduos Sólidos; altera a Lei no 9.605, de 12 de fevereiro de 1998; e dá outras providências. Diário Oficial da União. Brasília, BRASIL: DOU, 3 ago. 2010. Disponível em: <http://www.planalto.gov.br/ccivil_03/_ato20072010/2010/lei/l12305.htm>. Acesso em: 14 jul. 2017.

BRASIL. Ministério do Trabalho e Emprego. Classificação Brasileira de Ocupações Cbo. Descrição 5192: Catador de Material Reciclável: Trabalhadores da coleta e seleção de material reciclável, 2002. Disponível em: <http://www.ocupacoes.com.br/cbo-mte/519205catador-de-material-reciclave>. Acesso em: 10 jun. 2017.

CONCEIÇÃO, M. M. Os empresários do lixo: um paradoxo da modernidade: análise interdisciplinar das cooperativas de reciclagem de lixo. 2. ed. Campinas: Átomo, 2005.

CONCEIÇÃO, R.D. P. et al. A cadeia de reciclagem de pet pós-consumo e as definições de suas etapas: um estudo de caso no Rio de Janeiro. Revista Brasileira de Ciências Ambientais (online), [s.I.], Zeppelini Editorial e Comunicação, n. 39, p. 80-96, mar. 2016. Disponível em: <http://abes-dn. org.br/publicacoes/rbciamb/Ed39/RBCIAMB_n39_80-96.pdf>. Acesso em: 10 jun. 2017. 
EIGENHEER, E. M.; FERREIRA, J. A.; ADLER, R. R. Reciclagem: mito e realidade. Rio de Janeiro: In-fólio, 2005.

FUNDAÇÃO AVINA. Reciclagem Sustentável. Relatório Anual 2011. Ciudad del Saber, Clayton Panamá, República de Panamá, 2012. Disponível em: <http://www.informeavina2011.org/portugues/reciclaje.shtml>. Acesso em: 09 nov. 2017. Acesso em: 10 nov. 2017.

GIL, A. C. Como elaborar projetos de pesquisa. 5. ed. São Paulo: Atlas, 2008.

JACOBI, P. R. Gestão compartilhada dos resíduos sólidos no Brasil: inovação com inclusão social. São Paulo: Annablume, 2006.

MOREIRA, M. A. Mapas conceituais e aprendizagem significativa. Porto Alegre: Instituto de Física - UFRGS. Disponível em:

<https://www.if.ufrgs.br/ moreira/mapasport.pdf> Acesso em: 17 jul. 2017.

RIBEIRO, T. F.; LIMA, S. C. Coleta Seletiva de Lixo Domiciliar - Estudo de Casos. Caminhos De Geografia - Revista On Line Programa de PósGraduação em Geografia, Uberlândia, Instituto de Geografia - UFU 2000, v. 1, n. 2, p. 50-69 Disponível em: <http://www.seer.ufu.br/index.php/ caminhosdegeografia/article/viewFile/15253/8554>. Acesso em: 9 nov. 2017.

RUTKOWSKI, J. E.; VARELLA, C. V. S.; CAMPOS, L. S. A reciclagem de resíduos sólidos urbanos no Brasil: desafios e oportunidades para Ampliação. In: SEMINÁRIO NACIONAL DE RESÍDUOS SÓLIDOS, 11, 2014, Brasília. Anais... Brasília: Abes: Câmara Temática de Resíduos Sólidos da Abes, 2014. p. 1-15. Disponível em: <http://www.abes-df.org.br/upload/ estudo/2014_10_01/v-011.pdf>. Acesso em: 16 jul. 2017. 